\title{
Letter
}

\section{Consensus Statement from the European Network of 3R Centres (EU3Rnet)}

\author{
Winfried Neuhaus* \\ AIT - Austrian Institute of Technology GmbH, Center Health and Bioresources, Competence Unit Molecular Diagnostics, Vienna, Austria
}

\begin{abstract}
A Network of European 3R Centres (EU3Rnet) was established in connection with the EUSAAT conference in 2018 in order to strengthen cooperation between different centres. Increased cooperation has a multitude of benefits, since many of the efforts made by local or regional centres are of national and international importance. As an important step, the members have decided to publish a consensus statement for the network.
\end{abstract}

\section{Consensus Statement}

EU3Rnet embraces all of the 3Rs (Replacement, Reduction and Refinement) throughout its work, since the 3 Rs are the foundation of improved conditions for research animals and for better science.

EU3Rnet also considers it important to focus on Non-Animal Methods ${ }^{1}$ as part of its collaborative efforts. Non-Animal Methods have largely been developed further after the introduction of the 3R concept by Russell and Burch ${ }^{2}$ in 1959, thanks to technological advances in in vitro and in silico methods. EU3Rnet will therefore endeavour to promote this approach, so that researchers do not consider animal models by default when answering research questions, and instead consider the range of Non-Animal
Methods available, in order to avoid the unnecessary use of animal experimentation. When a relevant Non-Animal Method or an alternative Replacement method $^{3}$ to an animal model does not exist, the possibilities for Reduction and Refinement of the model must be examined.

EU3Rnet considers it important that internationally relevant national efforts to develop and promote the 3Rs and Non-Animal Methods are disseminated within the network. The network will disseminate such information to its members, who in turn will disseminate the information further through their communication channels (which include websites, newsletters, symposia, training activities, annual reports and other channels).

EU3Rnet will emphasize the importance of involving all members of the research animal community in these efforts to develop and disseminate $3 \mathrm{R}$ resources. These include animal carers, technologists, veterinarians, teachers, lecturers and scientists.

All of the 3R centres in EU3Rnet pledge themselves to prioritization of their dissemination efforts. Whenever possible, they will use publically available platforms to disseminate this knowledge, in order to maximize exposure.

\section{Participants of EU3Rnet, who agreed to the consensus statement:}

\begin{tabular}{|l|l|l|}
\hline Institution & Country & URL \\
\hline EUSAAT - European Society for Alternatives to Animal Testing & Europe & http://www.eusaat.org/ \\
\hline $\begin{array}{l}\text { Unit Ethics and Human-Animal Studies, } \\
\text { Messerli Research Institute, Vienna }\end{array}$ & Austria & $\begin{array}{l}\text { https://www.vetmeduni.ac.at/en/messerli/ } \\
\text { science/ethik/ }\end{array}$ \\
\hline The RepRefRed society / Austrian 3R Center & Austria & https://www.reprefred.eu/EN \\
\hline
\end{tabular}

\footnotetext{
${ }^{1}$ Non-animal methods are defined as totally animal-free methods, not using any animal component.

2 Russell, W. M. S. and Burch, R. L. (1959). The Principles of Humane Experimental Technique. https://caat.jhsph.edu/principles/the-principles-of-humane-experimental-technique

3 Replacement methods like in vitro methods might still be dependent on animal components such as fetal bovine serum or Matrigel.
}

* Winfried Neuhaus has submitted the Consensus Statement on behalf of all participating centres, institutes and societies of EU3Rnet.

Received October 6, 2020; (C) The Authors, 2020.

ALTEX 38(1), 138-139. doi:10.14573/altex.2010061

Correspondence: Coordinator Winfried Neuhaus

AIT - Austrian Institute of Technology GmbH,

Center Health and Bioresources,

Competence Unit Molecular Diagnostics,

Giefinggasse 4, 1210 Vienna, Austria

(winfried.neuhaus@ait.ac.at)
This is an Open Access article distributed under the terms of the Creative Commons Attribution 4.0 International license (http://creativecommons.org/licenses/by/4.0/) which permits unrestricted use, distribution and reproduction in any medium, provided the original work is appropriately cited. 


\begin{tabular}{|c|c|c|}
\hline Institution & Country & URL \\
\hline MUI animalFree Research Cluster & Austria & https://www.i-med.ac.at/muianimalfree/ \\
\hline Innovation Centre - 3R Alternatives (IC-3Rs) & Belgium & https://www.ic-3rs.org/ \\
\hline 3Rs Center Czech Republic & Czech Republic & http://www.szu.cz/ \\
\hline The Danish 3R-Center & Denmark & https://3rcenter.dk/ \\
\hline BB3R - Freie Universität Berlin & Germany & https://www.bb3r.de/ \\
\hline Charité $3^{R}$ - Charité - Universitätsmedizin Berlin & Germany & https://charite3r.charite.de/ \\
\hline $\begin{array}{l}\text { Leibniz Alternatives at IUF - Leibniz Research Institute for } \\
\text { Environmental Medicine }\end{array}$ & Germany & https://en.leibniz-alternatives.de/ \\
\hline R2N - „Replace“ und „Reduce“ aus Niedersachsen & Germany & https://r2n.eu/ \\
\hline TARC $_{\text {force }} 3 \mathrm{R}$ - Medical University Mainz & Germany & $\begin{array}{l}\text { https://www.unimedizin-mainz.de/tarc/ } \\
\text { tarc-force-3r.html }\end{array}$ \\
\hline ICAR3R - Interdisciplinary Center for 3Rs in Animal Research & Germany & http://www.ICAR3R.de \\
\hline Comparative Medicine, Trinity College Dublin & Ireland & https://www.tcd.ie/comparativemedicine/ \\
\hline $\begin{array}{l}\text { Centro3R: Italian Interuniversity Center for the Promotion } \\
\text { of the 3Rs Principles in Teaching and Research }\end{array}$ & Italy & http://www.centro3r.it/ \\
\hline LIST - Luxembourg Institute of Science and Technology & Luxembourg & https://www.list.lu/ \\
\hline Norecopa & Norway & https://norecopa.no/ \\
\hline ROCAM - Romanian Center for Alternative Test Methods & Romania & http://rocam.usamvcluj.ro/ \\
\hline $\begin{array}{l}\text { Slovak National Platform for 3Rs in Research, } \\
\text { Development and Education }\end{array}$ & Slovakia & https://www.snp3rs.com/ \\
\hline $\begin{array}{l}\text { CMCiB-IGTP - Comparative Medicine and Bioimage } \\
\text { Centre of Catalonia, Germans Trias i Pujol Research Institute }\end{array}$ & Spain & http://www.cmcib.cat/ \\
\hline The Swedish 3Rs Center & Sweden & https://www.jordbruksverket.se/3R \\
\hline Swiss 3RCC & Switzerland & https://www.swiss3rcc.org/en/ \\
\hline 3Rs-Centre of Utrecht University & The Netherlands & https://www.uu.nl/en/organisation/3rs-centre \\
\hline The National Centre for the 3Rs & UK & https://www.nc3rs.org.uk/ \\
\hline
\end{tabular}

The network is an entirely independent, open and free community, which is very much dependent upon initiatives of its protagonists and personal efforts. It is based upon a bottom-up approach, and every 3Rs-centre, institute or society is welcome to join the network and sign the consensus statement. 